NASA Technical Memorandum 107220

\title{
Vortex Generator Installation Studies on Steady State and Dynamic Inlet Distortion
}

Bernhard H. Anderson

Lewis Research Center

Cleveland, Ohio

and

James Gibb

Defence Research Agency

Bedford, England

Prepared for the

32nd Joint Propulsion Conference cosponsored by AIAA, ASME, SAE, and ASEE Lake Buena Vista, Florida, 1996

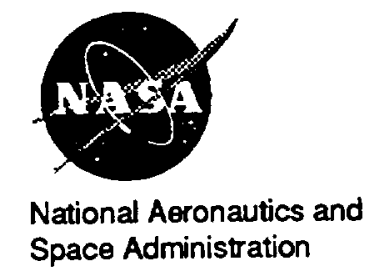


. 
VORTEX GENERATOR INSTALLATION STUDIES

ON STEADY STATE AND DYNAMIC INLET DISTORTION

by

Bernhard H. Anderson

NASA Lewis Research Center, Cleveland, Ohio 44135, USA

and

\author{
James Gibb \\ Defence Research Agency, Bedford, MK416AE, England
}

ABSTRACT

The theoretical and experimental work carried out under the NASAMMOD Joint Aeronautical Program has shown that CFD vortex generator installations designs successfully managed inlet duct flow distortion and that significant benefits in flow unsteadiness at the engine face were also present. The main conclusions to date from the collaborative effort between NASA/Lewis and DRA/Bedford are as follows: (1) vortex generator installations can be designed to be effective over a wide range of inlet operating conditions using Computational Fluid Dynamics and formal optimization procedures, (2) reductions in steady state engine face distortion of up to $80 \%$ have been measured in the M2129 inlet S-duct using CFD designed vortex generator installations, (3) reductions in flow unsteadiness of up to $80 \%$ have been measured in the M2129 inlet S-duct using CFD designed vortex generator installations, and (4) the Reduced Navier-Stokes code RNS3D is a useful tool to design vortex generator installations to manage engine face distortions over a wide range of inlet operating conditions.

\section{INTRODUCTION}

Engine face distortion is one of the most troublesome and least understood problems for designers of modem engine inlet systems. $1-2$ One issue is that there are numerous sources of flow field distortion that are ingested by the inlet or generated within the inlet duct itself. Among these sources are: (a) flow separation at the cowl lip during maneuvering flight, (b) flow separation on the compression surfaces due to shock-wave boundary layer interactions, (c) spillage of the fuselage boundary layer into the inlet duct, (d) ingestion of aircraft vortices and wakes emanating from upstream disturbances, and (e) secondary flow and possibly flow separation within the inlet duct itself. Most developing aircraft have experienced one or more of these types of problems, particularly at high Mach numbers and/or extreme maneuver conditions, such that flow distortion at the engine face exceeded the allowable limits of the engine. Such inletengine compatibility problems were encountered in the early versions of the $B 70$, the F-111, the F-14, the MIG-25, the Tornado and the Airbus A300.

The most common method of flow control in inlet ducts has been the inclusion of vane type vortex generators, the application of which is an extension of design methods used in external aerodynamics to 'locally' control the effects of separation. This is achieved by 'locally' mixing the low and high momentum regions in the flow which effectively spreads out the lower momentum fluid thus suppressing separation. However, engine face distortion is not often significantly reduced in three dimensional inlet $\mathbf{S}$-ducts, and the 'local' use of generators only allows separation to be controlled at one flow condition (usually the cruise condition), with all other flow conditions being 'off-design'.

The use of vortex generators within this study is viewed in an entirely different manner, i.e. the generators are used to 'globally" restructure secondary flow for the purpose of increasing inlet total pressure recovery and decreasing engine face distortion. The use of vortex generators as a 'global' method of secondary flow control was first proposed in two AIAA journal articles, namely: Anderson, Huang, Paschal, and Cavatorta ${ }^{3}$ for the re-engining program on the
727-100 center inlet duct using the TAY650 series engine. and by Anderson and Gibb ${ }^{4}$ for the DRA M2129 inlet S-duct. As a consequence of this conceph vortex generator installations can be optimized in terms of the inlet total pressure recovery and engine face distortion level over a wide range of inlet operating conditions. It is not a design criterion to prevent flow separation unless it produces an overall improvement in engine face flow characteristics. Therefore. the use of vortex generators as a "global' method of secondary flow control allows for the formal application of CFD and numerical optimization procedures to vortex generator installation design while encompassing a wide variety of inlet operating conditions.

The overall objectives of this are study is to advance the understanding, the prediction, and the control of inlet distortion, and to study the basic interactions that influence this important design problem. Early findings from this research activity have been reported by Anderson and $\mathrm{Gibb}^{4}$, Gibb and Jackson ${ }^{5}$, and by Gibb and Anderson ${ }^{6}$. and demonstrate that $C F D$ vortex generator installation designs can manage secondary flow and therefore represent a control method to suppress engine face steady state distortion. However, these early results indicated that maximum reductions in $\mathrm{DC}_{60}$ engine face distortion were not achieved due to the incorrect CFD prediction of the M2129 separation characteristics and the subsequent misplacement of the generator installation. The follow-on work under the NASA MOD Joint Aeronautical Program involved new CFD vortex generator installation designs based on the experimental separation characteristics measured in the DRA/Bedford $13 \mathrm{x}$ $9 \mathrm{ft}$. Wind Tunnel. This paper describes the latter findings and focuses on both the calculated and experimental performance results of the new CFD designed vortex generator installations for the DRA M2129 inlet S-duct.

\section{THEORETICAL BACKGROUND}

Three dimensional viscous subsonic flows in complex inlet duct geometries are investigated by a numerical procedure which allows solution by spatial forward marching integration, utilizing flow approximations 
from the velocity-decomposition approach of Briley and McDonald. ${ }^{7-8}$ The goal of this approach is to achieve a level of approximation that will yield accurate flow predictions. while reducing the labor below that needed to solve the full Navier-Stokes equations. The governing equations for this approach have been given previously for orthogonal coordinates. and the approach has been applied successfully to problems whose geometries can be fitted conveniently with orthogonal coordinate systems. However. geometries encountered in typical subsonic inlet ducts cannot be treated easily using orthogonal coordinates, and this led to an extension of this approach by Levy, Briley. and McDonald. to treat ducted geometries with nonorthogonal coordinates. In generalizing the geometry formulation. Anderson. ${ }^{10}$ extended the analysis to cover ducted geometries defined by an externally generated gridfile, such that it allowed for (1) reclustering the existing gridfile. (2) redefining the centerline space curve. and (3) altering the cross-sectional shape and area distribution without modifying the original gridfile. This version of the three dimensional Reduced Navier-Stokes computer code is called RNS3D. The turbulence model used in RNS3D is that of McDonald and Camarata ${ }^{11}$ which employes an eddy-viscosity formulation for the Reynolds stresses.

The analysis as presented here is applicable only when the primary velocity is not negative. Since "small" regions of reverse flow can arise in curved inlet ducts. the numerical method is locally modified to permit forward marching when the flow contains small regions of reverse flow. The technique used follows Reyhner and FluggeLotz. ${ }^{12}$ by adding small artificial convection at grid points where the primary flow is reversed. This is known as the FLARE approximation. after the authors. ${ }^{12}$ For thin regions of reverse flow. although the streamwise extent of flow separation can be very large compared to the length of the passage. the technique permits the analysis to proceed downstream beyond reattachment. confining the FLARE approximation to the separated region. The use of parabolized equations to treat separated flow of the type experienced in the M2129 inlet S-duct was investigated experimentally by Whitelaw and $\mathrm{Yu} .{ }^{13}$ and computationally by Anderson and Farikhi ${ }^{4}$ and Anderson. Reddy, and Kapoor. ${ }^{15}$ The vortex generator model that was used in this study was described by Kunik.16 and has demonstrated "good qualitative agreement with idealized and experimental results". The vortex generators are modelled as a spatial distributed step increase in vorticity within the governing equation.

\section{RESULTS AND DISCUSSIONS}

Experimental measurements were made on the ejector driven M2129 inlet S-duct shown installed in the DRA/Bedford $13 \times 9 \mathrm{ft}$ wind tunnel in Fig. (1). These tests were made using the configuration corresponding to the AGARD FDP Working Group 13 Test Case 3 defined by Willmer. Brown and Goldsmith. ${ }^{17}$ The original lip No. 4 and forward extension No. 3. were used for this study. The S-duct section of the M2129 inlet model was split along the axis of symmetry to facilitate fitting a variety of vortex generator configurations. The CFD analysis of the M2129 inlet S-duct was performed using RNS3D, and used a polar grid topology which consisted of 49 radial. 49 circumferential. and 107 streamwise nodal points to model the half-plane duct. for a total number of 256.907 grid points. Fig. (2). The CPU time was 6.3 minutes on the CRAY YMP for this computational grid. This large number of grid points was chosen in order to resolve the small interactions that are characteristic of vortex generator flow fields. The internal grid was constructed such that the transverse computational plane was perpendicular to the duct centerline. Grid clustering was used in the radial direction in order to resolve the high shear regions near the walls. The flow in the injet duct was considered turbulent

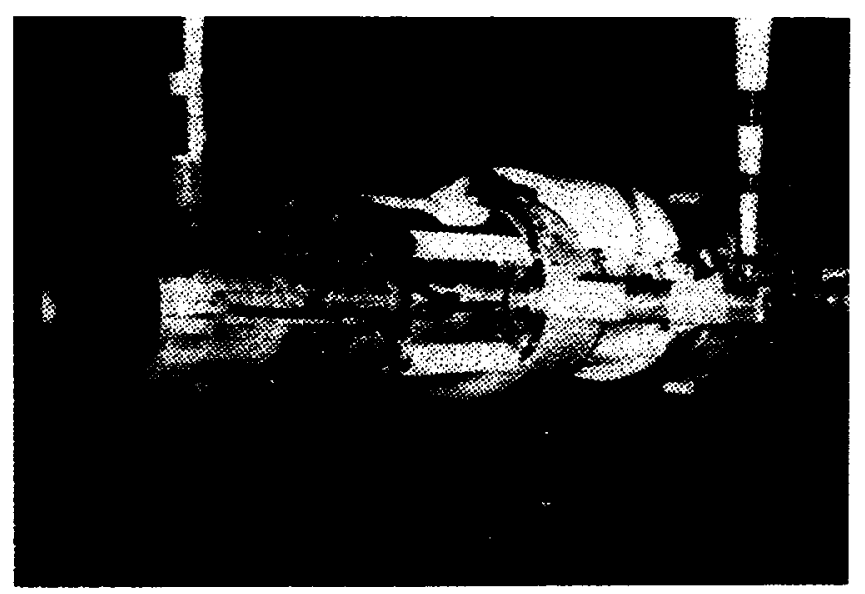

Fig. (1) M2129 inlet S-duct installed in the Bedford $13 \times 9$ ft. wind tunnel.

throughout. The inflow boundary-layer condition corresponds to a displacement thickness ratio. $\delta^{*} / R_{\mathrm{i}}$. of 0.018 . and was applied two inlet radii. $R_{i}$ upstream of the inlet throat in the No. 3 forward constant area extension. This boundary layer displacement thickness was chosen to provide the experimental inlet throat corrected weight flow values of $26.68 \mathrm{lbs} / \mathrm{sec}$ and $17.89 \mathrm{lbs} / \mathrm{sec}$ at the AGARD Test Case 3.1 and 3.2 conditions.

The relative engine-face distortion levels at different flight conditions are important since inlets must be designed to operate with low distortion over a flight envelope. Trades between what is needed at one flight condition (such as takeoff) and what is needed at other flight conditions (such as transonic maneuvering at low altitudes. or cruise) must be made. Mach number. Reynolds number. inlet corrected weight flow, and engine tolerance can all change

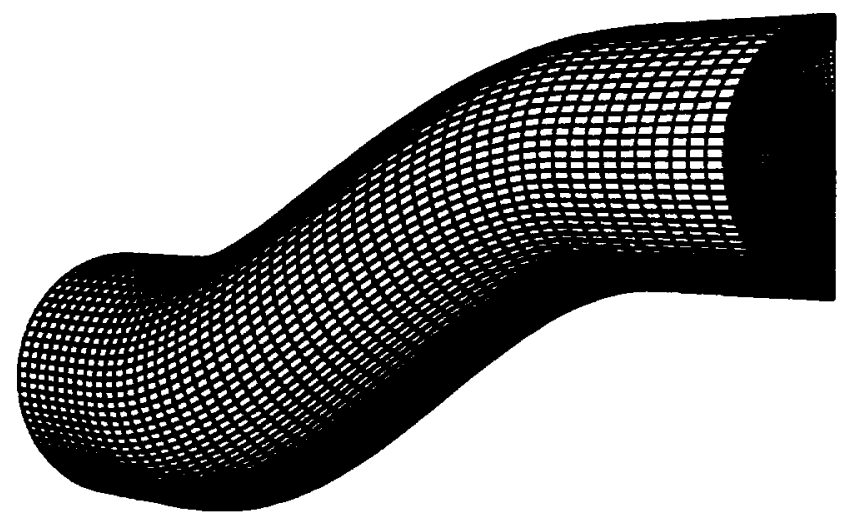

Fig. (2) Geometry and grid definition for the M2129 inlet S-duct. $L / R_{i}=7.10, A_{\text {ef }} / A_{i}=1.40 . \Delta Z / R_{i}=2.13$.

from one operating condition to another. It is. however. not necessary to solve the entire vortex generator optimization problem by varying every design parameter over the flight envelope of interest. Aspects of the generator installation design can and should be enhanced by a numerical optimization strategy. For example. in the present study. the vortex generator geometric angle-of-incidence. $\beta_{\mathrm{vg}}$ and height to chord ratio. $h / c$. were held fixed at $16.0^{\circ}$ and 0.250 respectively. Two fixed vortex generator installation 
locations, $\mathrm{X}_{\mathrm{vg}} / \mathrm{R}_{\mathrm{i}}$ were also chosen in the M2129 inlet $\mathrm{S}$-duct at 1.0 and 2.0 inlet radii. $R_{i}$ downstream of the inlet throat. (The significance of these two installation locations will be discussed in detail later in this paper.) Therefore. the optimization process involves the vortex generator height ratio. $h / R_{i}$, and the installation parameters of number of corotating vortex generator pairs, $\mathrm{n}_{\mathrm{vg}}$. angular spacing between vortex generators. $\alpha_{\text {vg. }}$ and the angular extent of the installation. $\theta_{5}$, which are all inter-related. These design parameters are defined in Figs. (3) and (4).

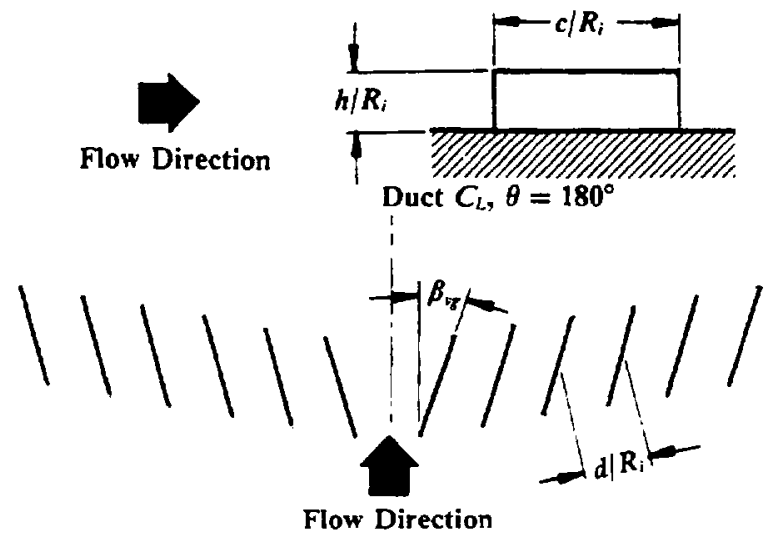

Fig. (3) Geometry definition for co-rotating vortex Generators

Selection of the performance parameter used to make judgements about the value of the generator installation is particularly interesting for three reasons. First. the required distortion level can be different at each important flight condition. Second. distortions levels greater than the engine tolerance are unacceptable whereas distortion levels less than the engine tolerance are of little value other than being less

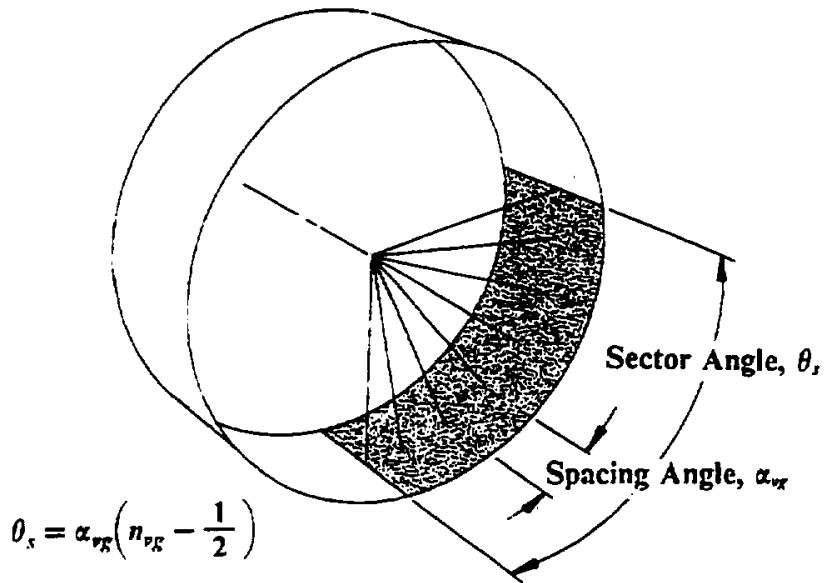

Fig. (4) Nomenclature used for vortex generator positioning.

than the engine distortion tolerance. Third. the engine itself must be defined since distortion descriptors are tied to an particular engine: there are no universal distortion descriptors. The importance of the engine face distortion descriptor lies in the fact that the final vortex generator installation that is acceptable will depend not only on the choice of descriptor. but also how that descriptor is determined. For examples, in this study the $\mathrm{DC}_{60}$ distortion descriptor will take on significantly different values depending whether this parameter is determined from an Inlet Operating Conditions $\begin{aligned}-M_{i} & =0.794 . \text { Rey }=1.849 \times 10^{6} \\ ---M_{i}=0.412 . & \text { Rey }=1.158 \times 10^{6}\end{aligned}$

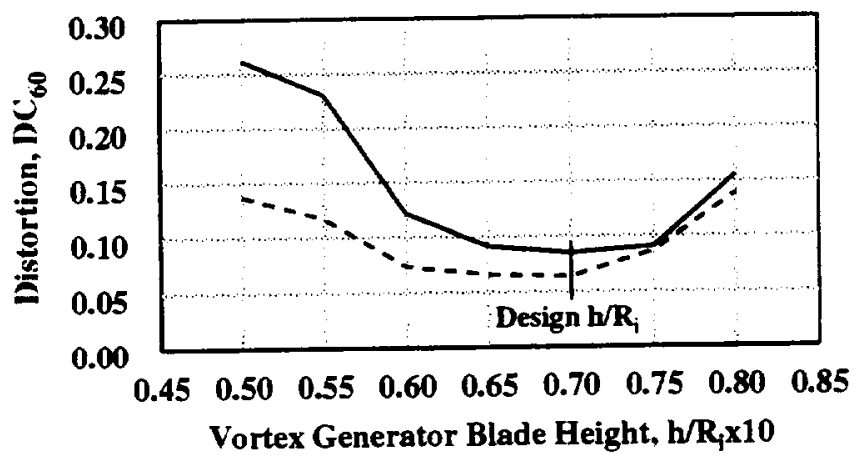

Fig. (5) Effect of vortex generator blade height on $\mathrm{DC}_{60}$ engine face steady state distortion.

integration of data on the computational mesh or whether a 72-probe interpolated data set was used with the experimental $\mathrm{DC}_{60}$ data reduction package. Therefore. the calculated inlet total pressure recovery levels and the distortion levels presented in this study were base on the same data reduction routines as used in the DRABedford experiments. The engine face flow unsteadiness parameter $\mathrm{Pt}_{\mathrm{rms}} / \mathrm{Q}$ presented in this paper was based on the average $\mathrm{mms}$ value of 8 pressure transducers spaced $45^{\circ}$ apart and located at $67 \%$ of the engine face radius.

Inlet Operating Conditlons

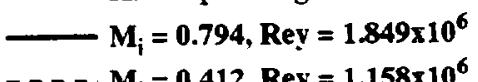

$-\ldots-M_{i}=0.412$. Rey $=1.158 \times 10^{6}$

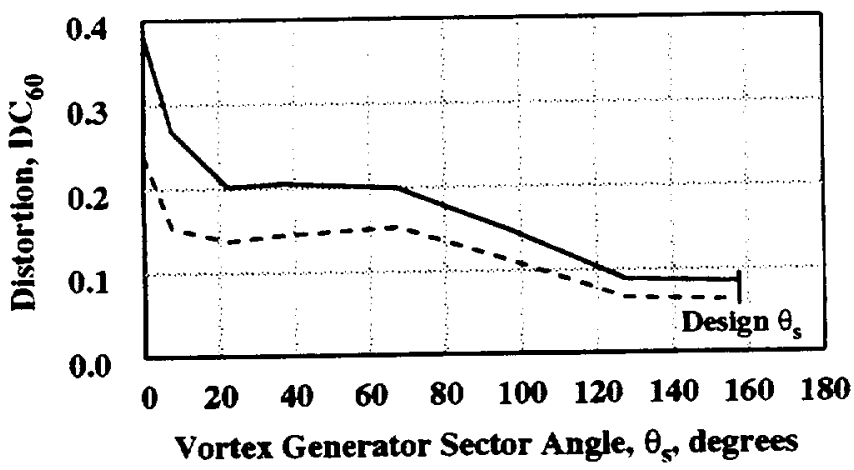

Fig. (6) Effect of vortex generator sector angle on $D C_{60}$ engine face distortion.

Each of the locally optimum vortex generator installations provided by NASA/Lewis was determined using numerical optimization techniques, however only the vortex generator installation located two inlet radii. $R_{\mathrm{i}}$ downstream of the inlet throat will be described in this paper. Both the engine face total pressure recovery $\mathrm{Pt}_{\text {ave }} / \mathrm{Pt}_{0}$ and $\mathrm{DC}_{60}$ levels were monitored during the optimization process. however. the total pressure recovery optimization characteristics are not presented here for the purpose of brevity. The design process begins using an installation composed of eleven corotating vortex generator pairs, each with an angular lateral spacing of $15.0^{\circ}$ and distributed over a sector angle of $157.5^{\circ}$ within the M2129 inlet S-duct. It does not matter which vortex generator configuration is used as the starting 
installation as long as the optimization process is completed

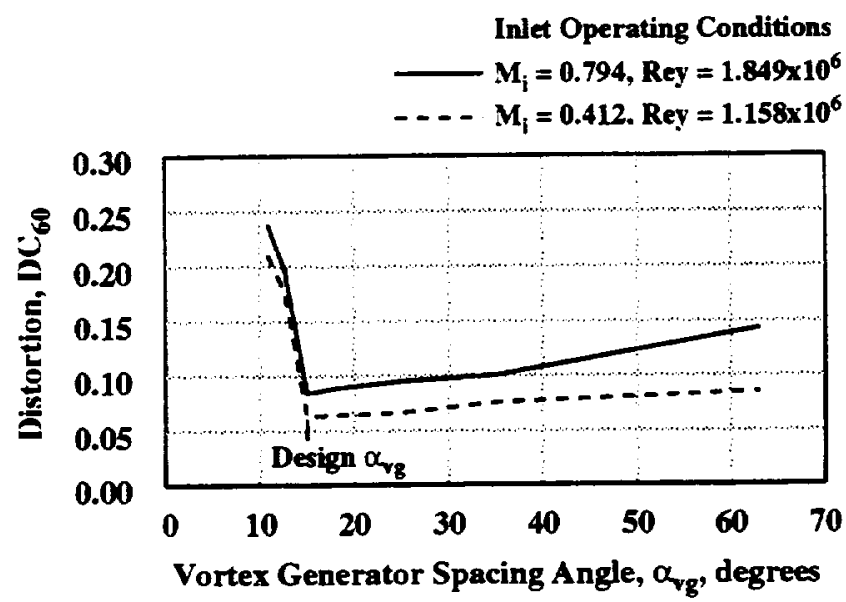

Fig. (7) Effect of vortex generator spacing angle on DC60 engine face distortion.

The standard blade section used in this study was composed of a low-aspect ratio flat-plate vane-type generator, where the aspect ratio. $\mathrm{b} / \mathrm{c}$. was set at 0.250 and the blade incidence angle. $\beta_{\mathrm{vg}}$ was set at $16.0^{\circ}$ for all configurations. It should be remembered that only a half-duct calculation was performed in this study, therefore the total number of vortex generators in the experimental duct was twice the number of generators used in the computational S-duct. Also, the other half of the M2129 inlet S-duct is the mirror image of the computational $\mathrm{S}$-duct. Therefore each co-rotating generator can be viewed as having a corresponding mirror image, i.e., the co-rotating generators can be labeled as pairs. A series of calculations using RNS3D were performed over a range of vortex

\begin{tabular}{|c|c|c|c|c|}
\hline Designation & VG130 & VG160 & VG165 & VG170 \\
\hline Vumber of Pairs, $\mathrm{n}_{\mathrm{gg}}$ & 11 & 13 & 11 & 11 \\
\hline Sector Location, $\mathbf{X}_{v_{g}} / R_{i}$ & 3.0 & 1.0 & 1.0 & 2.0 \\
\hline Blade Keight, $h / R_{i}$ & 0.075 & 0.060 & 0.065 & 0.070 \\
\hline Chord Length, $c \mathbf{R}_{\mathbf{i}}$ & 0.300 & 0.240 & 0.260 & 0.280 \\
\hline Lateral Spacing, $\mathbf{d} / \mathbf{R}_{\mathbf{i}}$ & 0.289 & 0.224 & 0.267 & 0.277 \\
\hline Spacing Angle, $\alpha_{v g}$ & $15.0^{\circ}$ & $12.6^{\circ}$ & $15.0^{\circ}$ & $15.0^{\circ}$ \\
\hline Angle of Incidence, $\beta_{\mathrm{ve}}$ & $16.0^{\circ}$ & $16.0^{\circ}$ & $16.0^{\circ}$ & $16.0^{\circ}$ \\
\hline Sector Angle, $\theta_{3}$ & $157.5^{\circ}$ & $157.5^{\circ}$ & $157.5^{\circ}$ & $157.5^{\circ}$ \\
\hline
\end{tabular}

Table (1) Matrix of CFD designed vortex generator installation tested in the Bedford $13 \times 9 \mathrm{ft}$. wind tunnel.

generator blade heights. $h / R_{i}$, from 0.050 to 0.080 for inlet throat Mach number conditions of 0.794 and 0.412 . These inlet operating conditions correspond to the AGARD FDP Working Group 13 Test Cases 3.1 and 3.2 respectively. The effect of generator blade height on $\mathrm{DC}_{60}$ engine face distortion is presented in Fig. (5) and indicates that a blade height of 0.070 would provide the lowest overall distortion level over the nominal inlet throat Mach number range from 0.4 to 0.8 . Although. the design objective was to optimize over the nominal throat Mach number range from 0.2 to 0.8 . experience has demonstrated that it is not necessary to consider inlet throat Mach numbers below 0.4 for this type of study. To demonstrate that this vortex generator installation indeed represents a "local optimum" configuration. a series of calculations were performed over a range of generator sector angles from $0.0^{\circ}$ to $157.5^{\circ}$ (at a fixed spacing angle of $15.0^{\circ}$ ). Fig. (6), as well as a range of spacing angles from $12.6^{\circ}$ to $63.0^{\circ}$ (at a constant sector angle of $157.0^{\circ}$ ). Fig. (7). These results substantiated that the a sector angle of $157.5^{\circ}$ and spacing angle of $15.0^{\circ}$ provided the lowest overall distortion level over the nominal inlet throat Mach number range from 0.2 to 0.8 . This vortex generator installation was labeled as VG170. In like manner. vortex generator installations VG160 and VG165 were also determined to be 'locally optimum" configurations.

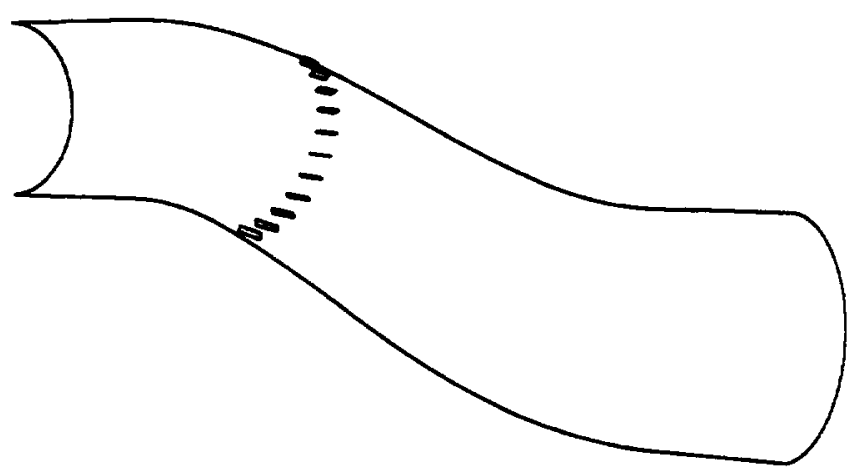

Fig. (8) Vortex generator configuration VG170 installed in the DRA M2129 inlet S-duct.

The matrix of CFD designed vortex generator installations tested in the DRA/Bedford $13 \times 9 \mathrm{ft}$. Wind Tunnel are presented in Table I. The important geometric parameters for vortex generator installation design includes (1) the number of vortex generator pairs, $n_{\mathrm{vg}}$. (2) the generator sector axial location. $X_{v g} / R_{i}$ (3) the vortex generator blade height. $h / R_{i}$, (4) the vơrtex generator chord length, $c / R_{i},(5)$ the lateral spacing between generator blades.

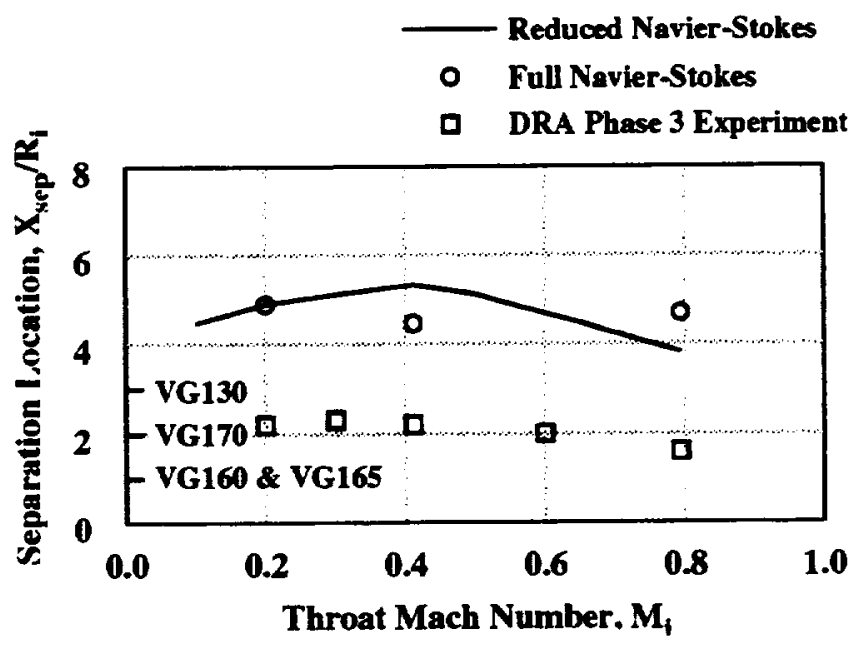

Fig. (9) Computed and measured separation characteristics in the M2129 baseline inlet S-duct.

$d / R_{j}$ (6) the lateral spacing angle, $\alpha_{v g}$. which is equivalent to the lateral spacing parameter. $d / \mathbf{R}_{\mathrm{i}},(7)$ the vortex generator blade angle-of-incidence. $\beta_{\mathrm{vg}}$. and $(8)$ the installation sector angle. $\theta_{s}$, which is a function of both the number of vortex generator pairs $n_{v g}$ and generator spacing angle. $\alpha_{\mathrm{vg}}$. There can be many more vortex generator design parameters. For example, it may be advantages to vary the height of the 
generator blades in the circumferential direction, or to have more than one generator installation location. or to use a mix of counter-rotating and co-rotating vortex generators. It should be restated that it is not necessary to solve the entire vortex generator optimization problem using all the design parameters over the flight envelope of interest. Aspects of the generator installation design can and should be enhanced by a numerical optimization strategy based on a common sense
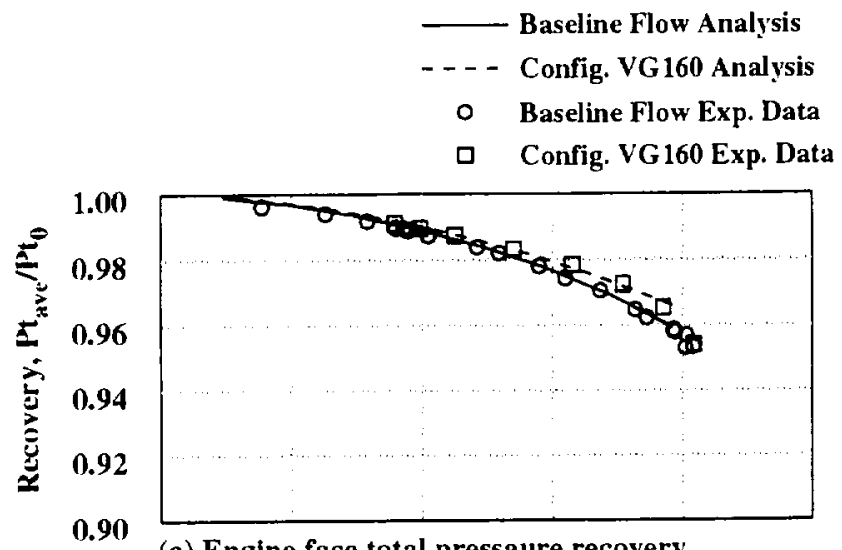

(a) Engine face total pressaure recovery
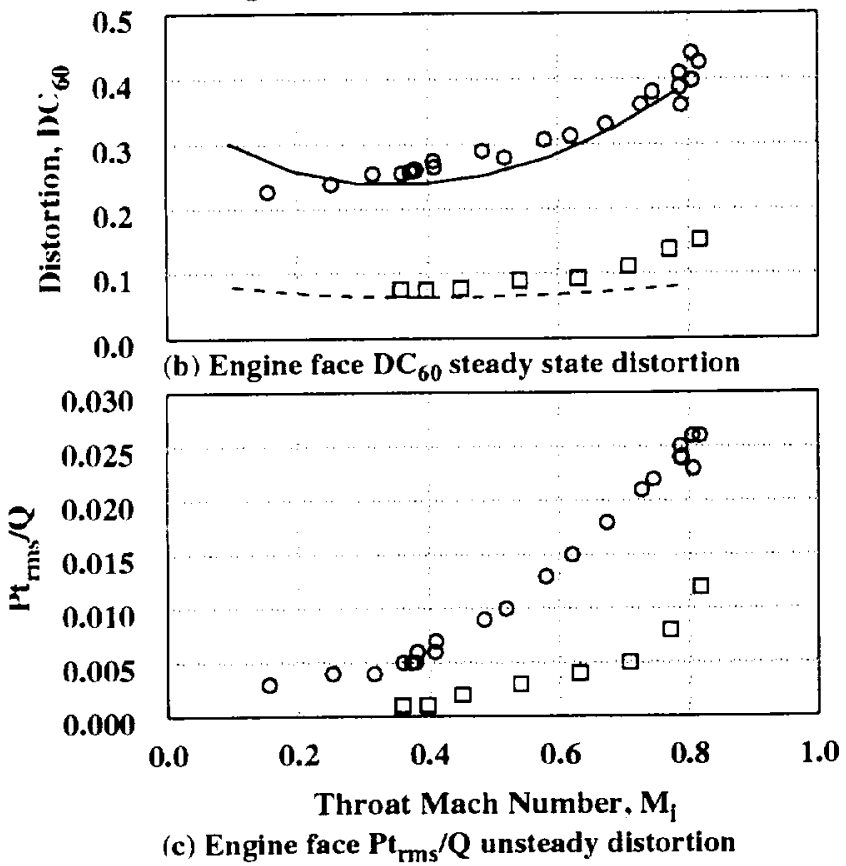

Fig. (10) Effect of vortex generator configuration VG160 on the M2129 inlet S-duct performance.

understanding of how vortex generators operate as an installation. Figure (8) shows a half-plane schematic illustration of vortex generator configuration VG170 installed in the DRA M2129 inlet S-duct. The relationship between the location of the family of vortex generator installations $\mathrm{X}_{\mathrm{vg}} / \mathrm{R}_{\mathrm{i}}$ presented in Table $\mathrm{I}$ and both the experimental and computed separation characteristics are presented in Fig. (9). Both Full Navier-Stokes and Reduced Navier-Stokes analysis of the separation characteristics were performed for the M2129 baseline S-duct inlet using algebraic turbulence models. ${ }^{15}$ Vortex generator configurations VG160 and VG165 were located within the M2129 S-duct at a one inlet radii $R_{i}$ downstream of the inlet throat such that the experimental flow separation encountered over the inlet Mach number ranged tested was always downstream of the generator installation. Vortex generator configuration VG170, however was located at two inlet radii. $R_{j}$, downstream of the inlet throat. Fig. (8). At this axial station, the separation moved "slightly" into the generator region at the higher inlet throat Mach number flow regime, Fig. (9). Since the vortex generators in the 'good' flow can

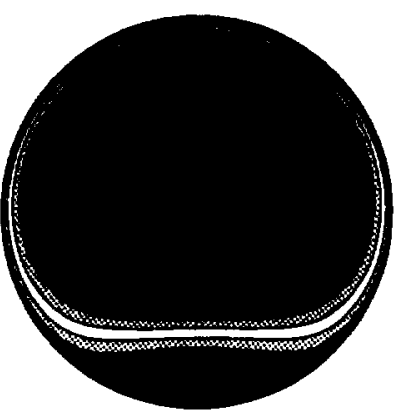

(a) NASA RNS3D Analysis

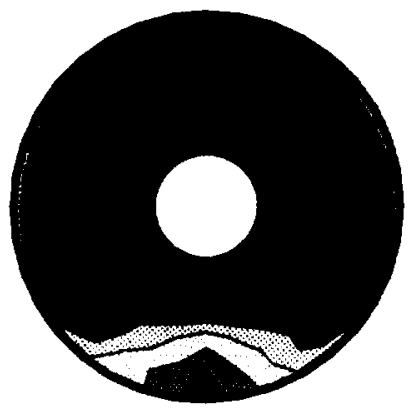

(b) DRA Experimental Data
Fig. (11) Comparison of calculated and experimental engine face total pressure recovery contours for the M2129 baseline flow, nominal throat Mach number $\mathrm{Mi}=0.4$

still reverse the effects of secondary flow. acceptable performance can still be achieved. Vortex generator installation VG130 was designed relative to computed separation characteristics, which were well downstream of

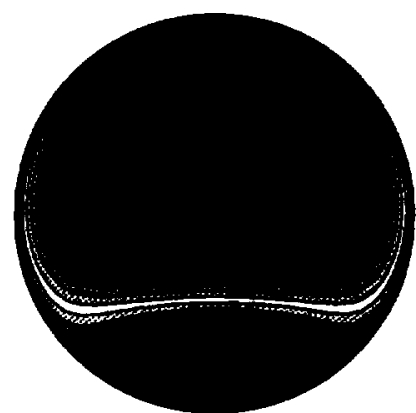

(a) NASA RNS3D Analysis

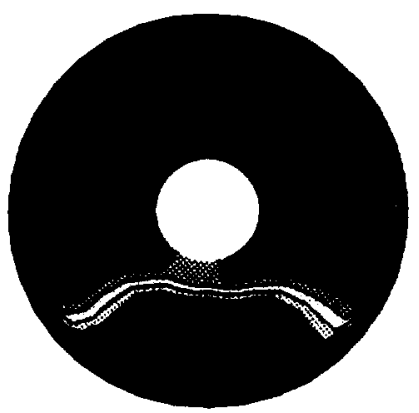

(b) DRA Experimental Data
Fig. (12) Comparison of calculated and experimental engine face total pressure recovery contours for the M2129 baseline flow, nominal throat Mach number $\mathrm{Mi}=\mathbf{0 . 8}$.

the actual (experimental) separation characteristics. In the lower Mach Number range, this generator installation reduced $\mathrm{DC}_{60}$ engine face distortion about $75 \%$. while at the higher inlet throat Mach number region. only a $25 \%$ reduction in steady state distortion was realized. Hence this installation did not perform as well as desired. although these are remarkable performance gains for a vortex generator installation located in the middle of a strongly separated flow region.

The three vortex generator configurations VG160. VG165 and VG170 that were tested all represent local optimum' installation designs as obtained using the Reduced Navier-Stokes code RNS3D. Vortex generators installations VG160 and VG165 were located at an axial position one inlet radii $R_{j}$ downstream of the inlet throat. which was always upstream of the most forward flow separation (vortex lift-off) 
location measured over the throat Mach number range tested. The generator installations VG160 and VG165 differed in the number of vortex generator pairs, the vortex generator blade height, and both lateral and angular spacing, Table I. The performance of vortex generator installations VG160 and

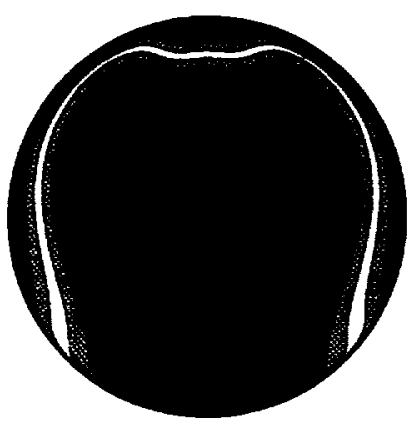

(a) NASA RNS3D Analysis

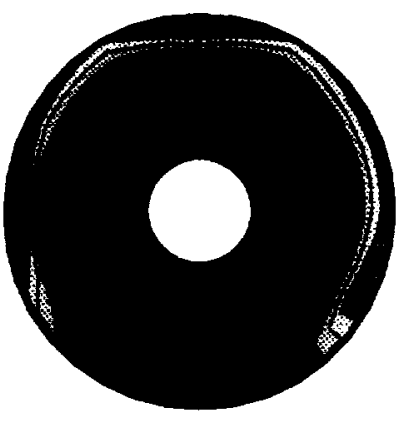

(b) DRA Experimental Data
Fig. (13) Comparison of calculated and experimental engine face total pressure recovery contours for generator configuration VG160, nominal throat Mach number $\mathrm{Mi}=\mathbf{0 . 4}$.

VG165, including a comparison between the calculated and measured engine face flow fields. are presented in Fig. (10) through Fig. (17). Figure (10) shows the overall effect of vortex installation $\mathrm{V} G 160$ on the inlet total pressure recovery, $\mathrm{Pt}_{\text {ave }} / \mathrm{Pt}_{0}$, Fig. (10a), the $\mathrm{DC}_{60}$ steady state engine face distortion. Fig. (10b), the rms of total pressure fluctuations. $\mathrm{Pt}_{\mathrm{rms}} / \mathrm{Q}$, at the engine face, Fig. (10c), as compared to the baseline or 'empty' M2129 inlet duct. The benefits in total pressure recovery, engine face steady state

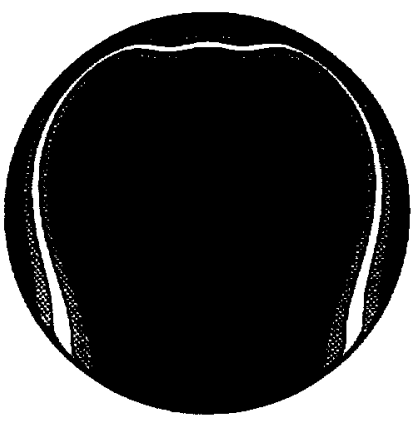

(a) NASA RNS3D Analysis

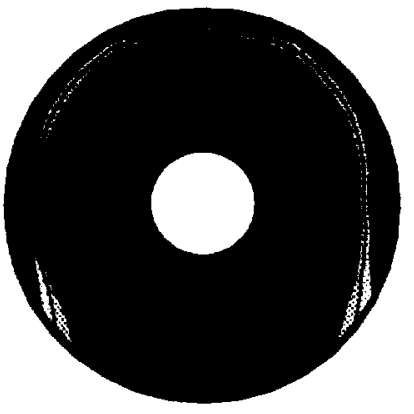

(b) DRA Experimental Data
Fig. (14) Comparison of calculated and experimental engine face total pressure recovery contours for generator configuration VG160, nominal throat Mach number $\mathrm{Mi}=0.8$.

distortion. and engine face total pressure fluctuations as a consequence of vortex installation VG160 are clearly seen. When the effects of generator installation VG160 are compared to the "empty" or baseline performance. reductions in engine face distortion of nearly $80 \%$ were realized. Comparing the calculated (solid and dashed lines) with the experimental (circular and square symbols) inlet performance indicates very good agreement in predicting total pressure recovery, but an over predicting the effect of generator installation VG160 on $\mathrm{DC}_{60}$ engine face distortion at the higher inlet throat Mach numbers, Fig. (10b). Figures (11) through (14) present a comparison between the calculated and measured engine face total pressure recovery contours at nominal inlet throat Mach of 0.4 and 0.8 for both the baseline
S-duct. Figs. (10) and (11), as well as for vortex generator installation VG160. Figs. (13) and (14). A comparison between engine face baseline recovery contours at nominal throat Mach numbers of 0.4 and 0.8. Figs. (11) and (12). and the engine face recovery contours for VG160. Figs. (13) and (14), indicates that optimally designed vortex generator installations tend to distribute the low energy flow uniformly

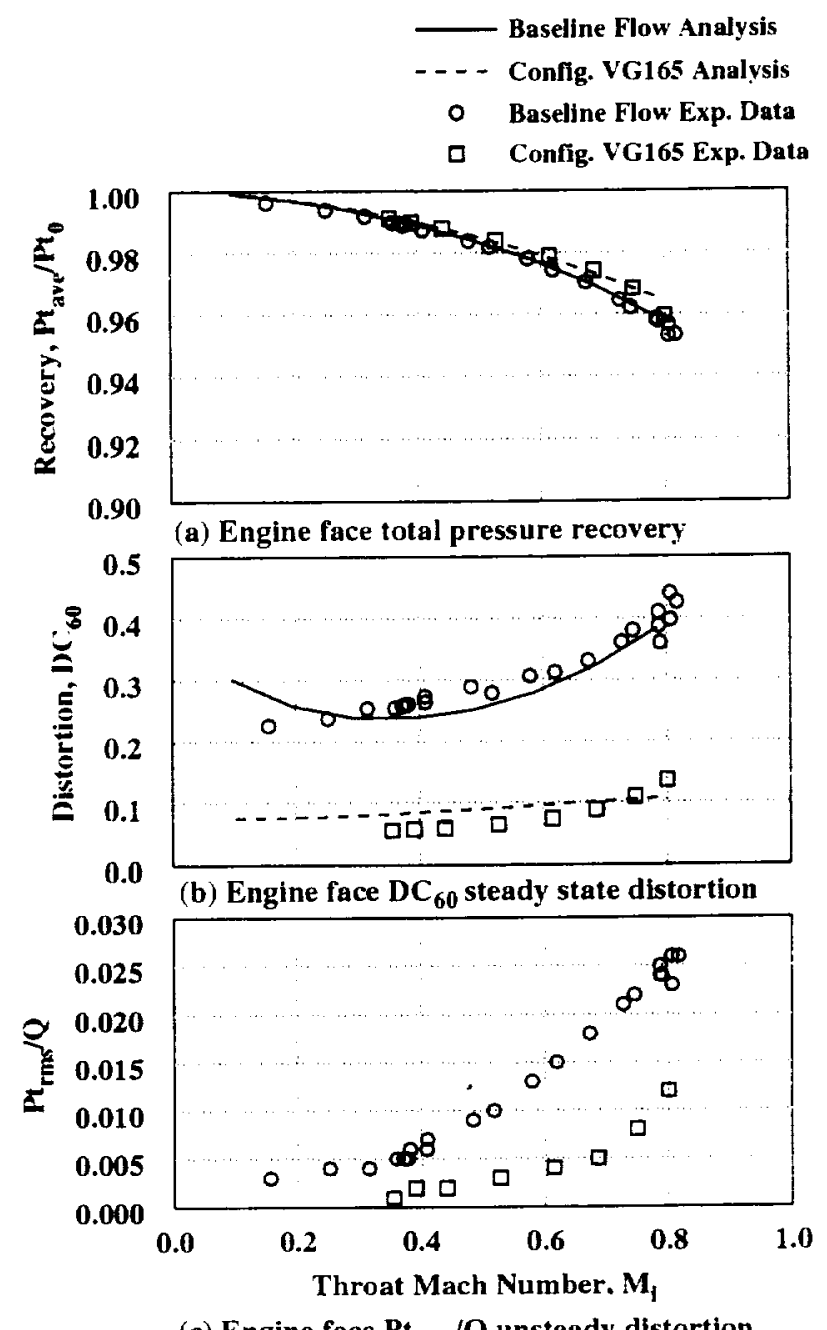

(c) Engine face $\mathbf{P t}_{\mathbf{r m s}} / \mathbf{Q}$ unsteady distortion

Fig. (15) Effect of vortex generator configuration VG165 on the M2129 inlet S-duct performance.

around the inside periphery of the engine face. leaving a high energy core flow. In general, the agreement between analysis and measurement is quite good at both inlet throat Mach numbers. However, at a nominal inlet throat Mach number of

0.8 , the measured engine face total pressure contours indicated a 'bad' tube at the $90^{\circ}$ degree rake location. Fig. (14). This 'bad' tube reading, the effect of which tended to increase with increasing inlet throat Mach number. was included in the $\mathrm{DC}_{60}$ measured distortion results. and could clearly explain the difference between the calculated and measured distortion presented in Fig. (10b). Very similar performance improvements were obtained with vortex generator installation VG165 relative to the baseline $S$-duct performance, Fig. (15). Again. the agreement between analysis and measurements was very good. except for the tendency to over predict the effect of $V G 165$ on $D_{60}$ steady state engine face distortion. Fig. (14b) at the higher inlet 
throat Mach numbers. However, the same 'bad' tube reading was still present in the measured VG165 engine total pressure results, Figs. (16) and (17).

Vortex generators installation VG170 was located two inlet radii. $R_{j}$. downstream of the inlet throat. Fig. (8). At this generator installation location. the separation was "slightly' downstream of the generators at the lower inlet

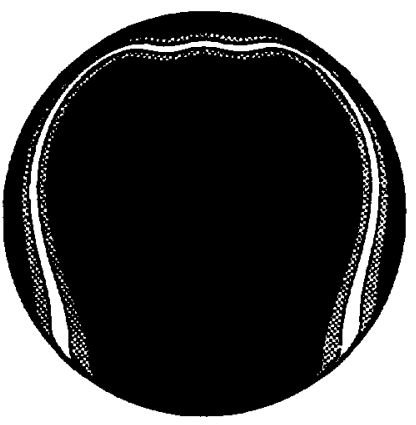

(a) NASA RNS3D Analysis

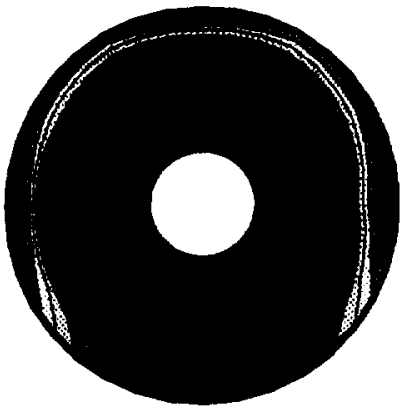

(b) DRA Experimental Data
Fig. (16) Comparison of calculated and experimental engine face total pressure recovery contours for generator configuration VG165, nominal throat Mach number $\mathrm{Mi}=0.4$.

throat Mach numbers but "slightly" upstream at the higher inlet throat Mach numbers. Fig. (9). Figure (18) presents the effects of vortex generator configuration VG170 on the inlet total pressure recovery. Fig. (18a). the $\mathrm{DC}_{60}$ steady state engine face distortion, Fig. (18b), and the rms of total pressure fluctuations $\mathrm{Pt}_{\mathrm{rms}} / \mathrm{Q}$ at the engine face. Fig. (18c). The results of the RNS3D analysis and DRA experiments on the $V G 170$ vane type generator installation are compared

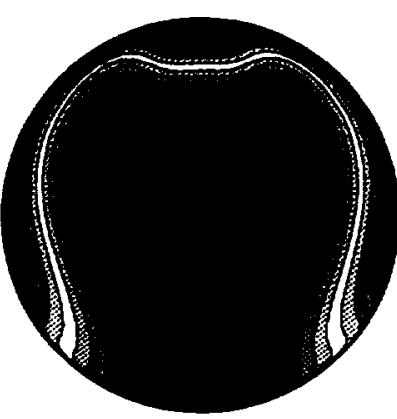

(a) NASA RNS3D Analysis

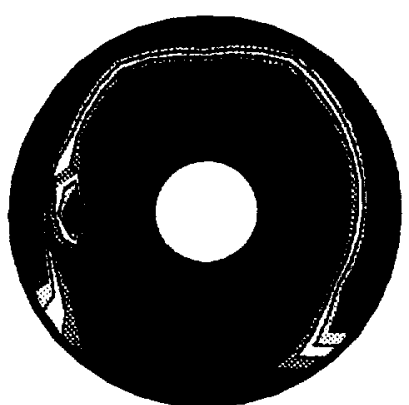

(b) DRA Experimental Data
Fig. (17) Comparison of calculated and experimental engine face total pressure recovery contours for generator configuration VG165, nominal throat Mach number $\mathrm{Mi}=\mathbf{0 . 8}$.

with the M2129 empty baseline S-duct flow. The benefits in total pressure recovery, engine face steady state distortion. and engine face total pressure fluctuations are clearly seen. When the effect of the vane-type vortex generators are compared to the empty baseline performance, reductions distortion of nearly $80 \%$ are realized at the higher throat inlet Mach numbers. Similar percentage reductions in engine face distortion can be seen at the lower inlet throat Mach numbers. but here the lower baseline S-duct distortions are less of a problem. This is true both for the RNS3D analysis prediction (solid and dashed lines) and DRA experimental results (circular and square symbols) of the baseline empty S-duct and vortex generator configuration VG170. which are in remarkably good agreement. A further benefit of the 'global' approach to vortex generator installation design is that the generators themselves can be partially located in the separation region, as is the case with the VG170 installation at the high inlet throat Mach numbers. Since the vortex generators in the 'good' flow can still reverse the effects of secondary flow, very acceptable performance was achieved. In fact. the performance results of configuration VG170 presented in Fig. (18) suggests that 'global' management of partially separated or 'spoiled' flow can even produce better overall optimum vortex generator installation performance than the management of attached or 'unspoiled' flow'.
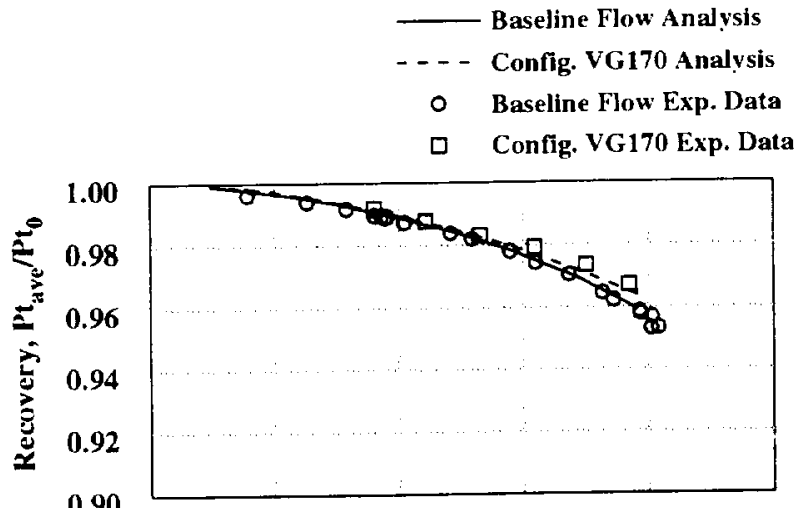

(a) Engine face total pressure recovery
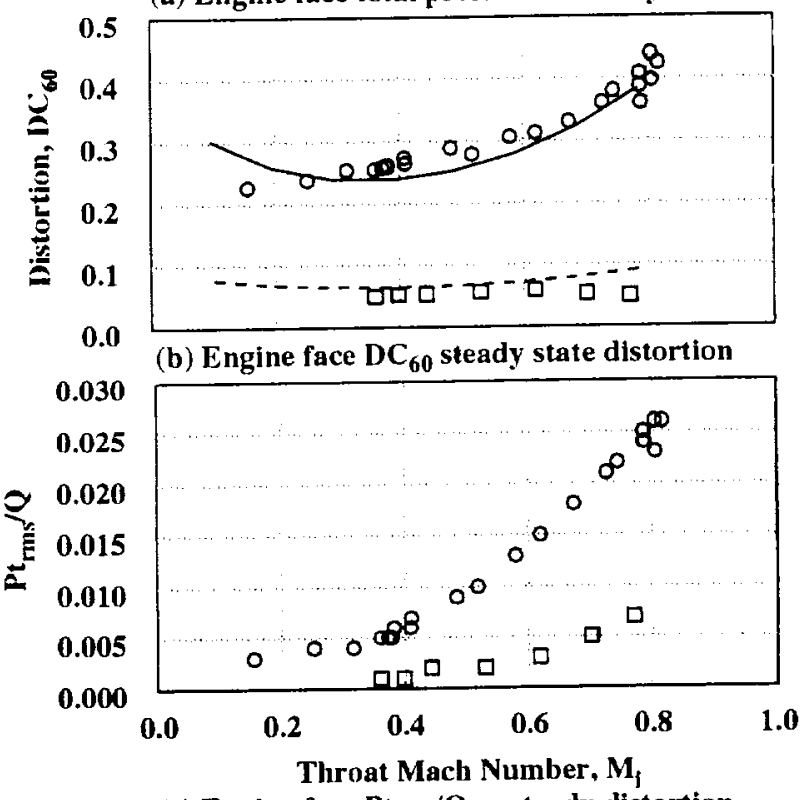

(c) Engine face $\mathrm{Pt}_{\mathrm{rms}} / \mathrm{Q}$ unsteady distortion

Fig. (18) Effect of vortex generator configuration VG170 on the M2129 inlet S-duct performance.

Shown in Fig. (19) is a comparison between the calculated and measured engine face ring distortion descriptors at nominal inlet throat Mach numbers of 0.4 and 0.8 for vortex generator configuration VG170. These descriptors include the engine face ring total pressure recovery distribution, Fig. (19a), the radial ring distortion. Fig. (19b), and the $60^{\circ}$-sector circumferential ring distortion. Fig. $(19 \mathrm{c})$. The quantitative agreement between the RNS3D analysis and the DRA experimental is very good. A comparison between the calculated and measured engine face total pressure recovery contours for vortex generator 

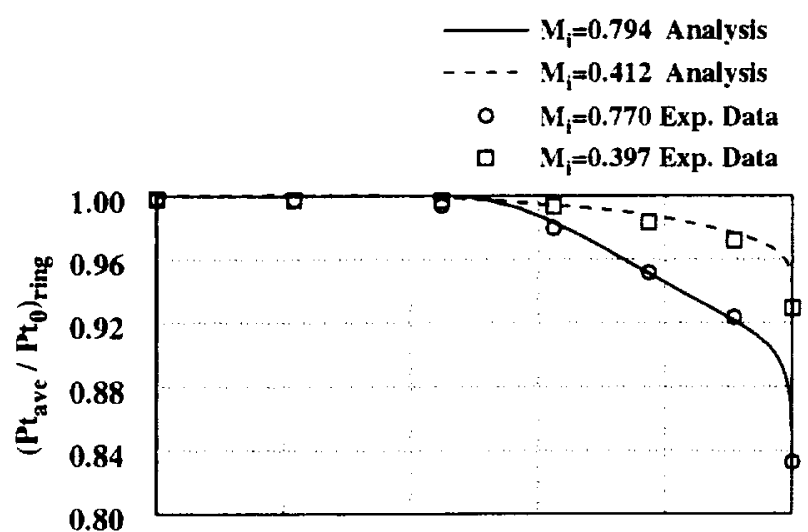

(a) Engine face ring total pressure recovery

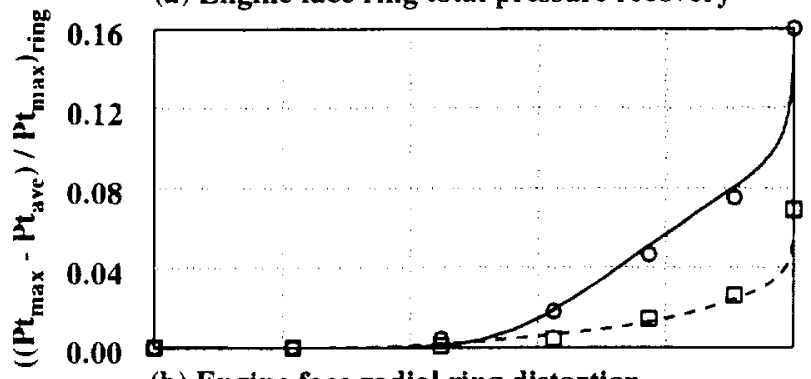

(b) Engine face radial ring distortion

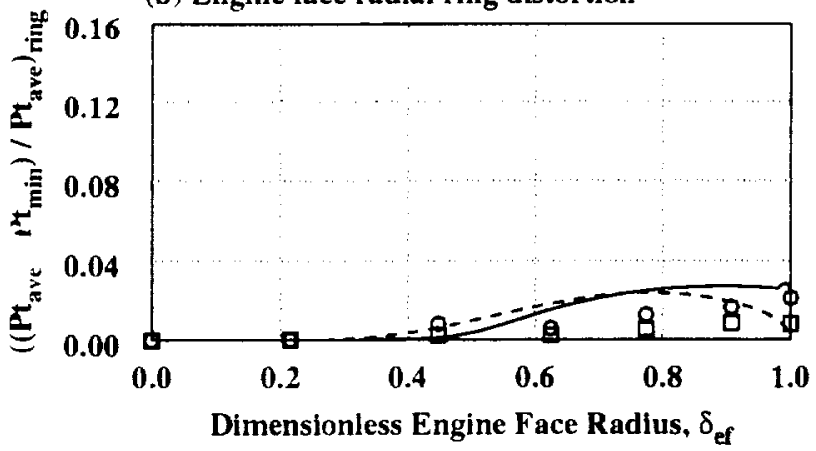

(c) Engine face $60^{\circ}$-sector circumferential distortion

Fig. (19) Effect of vortex generator configuration VG170 on the M2129 inlet S-duct engine face distortion.

configuration VG170 are presented in Figs. (20) and (21) for nominal inlet throat Mach numbers of 0.4 and 0.8 respectively and show good agreement. Likewise, a comparison between engine face baseline recovery contours at nominal throat Mach numbers of 0.4 and 0.8. Figs. (11) and (12). and the engine face recovery contours for VG170, Figs. (20) and (21). indicate that optimally designed vortex generator installations tend to distribute the low energy flow uniformly around the inside periphery of the engine face, leaving a high energy core flow.

\section{CONCLUDING REMARKS}

The three vortex generator configurations VGI60. VG165 and VG170, that were tested under the NASA/MOD Joint Aeronautical Program in the DRA/Bedford $13 \times 9 \mathrm{ft}$. Wind Tunnel, all represent 'local optimum' installation designs as provided by NASA/Lewis using the Reduced Navier-Stokes code RNS3D. The performance improvements realized over the baseline M2129 inlet S-duct for these three installation designs were as much as $80 \%$ reduction in steady state $\mathrm{DC}_{60}$ engine face distortion and $80 \%$ reduction in $\mathrm{Pt}_{\text {tms }}$ $Q$ engine face dynamic distortion. It is also evident from the results presented in this paper that restructuring the secondary flow to maximize total pressure recovery and minimize engine face $\mathrm{DC}_{60}$ distortion using optimization procedures has the effect of searching for a generator installation which distributes the low energy flow uniformly around the inside periphery of the engine face, leaving a high energy core flow. Lastly, the experimental data obtained at DRA/Bedford demonstrates conclusively that optimally designed vortex generator installations using Computation Fluid Dynamics (CFD) can greatly suppress both steady state and dynamic engine face distortion.

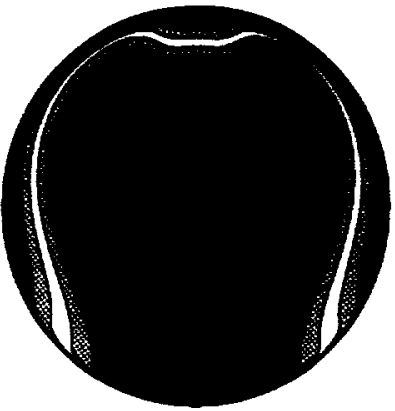

(a) NASA RNS3D Analysis

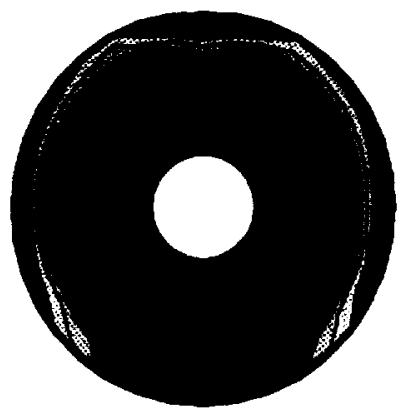

(b) DRA Experimental Data
Fig. (20) Comparison of calculated and experimental engine face total pressure recovery contours for generator configuration VG170, nominal throat Mach number $M i=0.4$.

The use of vortex generators as a 'global' method of secondary flow control allowed for the formal application of optimization procedures to be used with the NASA/Lewis Reduced Navier-Stokes code RNS3D. while encompassing a wide variety of inlet flow conditions. The vortex generators

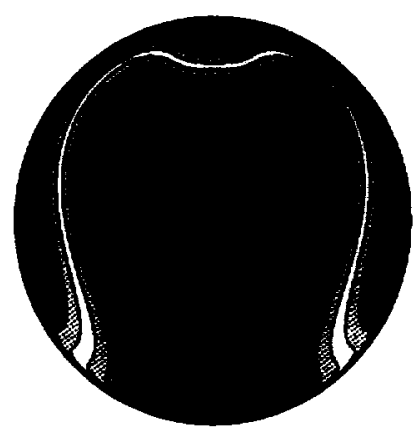

(a) NASA RNS3D Analysis

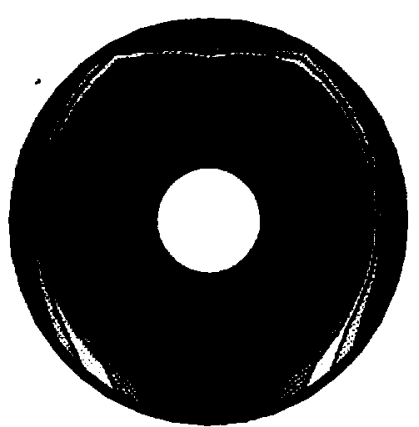

(b) DRA Experimental Data

Fig. (21) Comparison of calculated and experimental engine face total pressure recovery contours for generator configuration VG170, nominal throat Mach number $\mathrm{Mi}=\mathbf{0 . 8}$.

were optimized in terms of engine face total pressure recovery $\mathrm{Pt}_{\text {ave }} / \mathrm{Pt}_{0}$ and $\mathrm{DC}_{60}$ engine face distortion levels from the $\mathrm{M} 2129$ inlet $\mathrm{S}$-duct. It was not a design criterion to prevent separation unless it produced an overall improvement in the engine face flow characteristics. A further benefit of the 'global' approach to vortex generator installation design is that the generators themselves can be partially located in the separation region, as is the case with the VG170 installation at the high inlet throat Mach numbers. Since the vortex generators in the 'good' flow can still reverse the effects of secondary flow, good performance was still achieved. In fact. the performance results of configuration VG170 suggest that 
'global' management of partially separated or 'spoiled' flow can even produce better overall optimum vortex generator installation performance than the management of attached flow.

The computer code used to design the vortex generator installation presented in this paper is the three dimensional Reduced Navier-Stokes code RNS3D. The vortex generators are not directly computed. but rather the effect of the vortex generator was fed in as a spatially distributed step increase in vorticity in the goveming equations. There are two modelling issues related to this approach. namely (1) the form of the spatial vorticity signature created by the individual generators, and (2) the relationship between the physical geometry of the generators and the strength of vortex produced. Both of these issues are currently being studied. and improved vortex generator modelling is underway in RNS3D. However. the overall agreement between analysis and experiment is excellent. This substantiates the use of vortex generator models in Reduced Navier-Stokes analyses as a valid approach to vortex generator installation design. and suggests that this approach is also valid for Full Navier-Stokes analysis.

\section{REFERENCES}

${ }^{1}$ Advisory Group for Aerospace Research and Development (AGARD). "Engine Response to Distorted Inflow Conditions," AGARD CP-400, Munich, Germany, Sept. 1986.

${ }^{2}$ Bowditch. D. N. and Coltrin. R. E.. "A Survey of Inlet/ Engine Distortion Compatibility." AIAA Paper No. 83-1166, 1986.

3 Anderson. B. H.. Huang, P. S.. Paschal. W. A. and Cavatorta. E.. "Study of Vortex Flow Control of Inlet Distortion: Journal of Propulsion and Power. Volume 8, Number 6. November-December 1992, pp 1266-1272.

4 Anderson. B. H. and Gibb. J.. "Study on Vortex Generator Flow Control for the Management of Inlet Distortion, Joumal of Propulsion and Power, Volume 9. Number 3, May-June 1993. pp 420-430.

${ }^{5}$ Gibb. J. and Jackson, M.. "Some Preliminary Results From Tests Using Vortex Generators in the Circular/Circular Diffusing S-Duct Model M Report AP4(92)WP15. Aug. 1992.

6 Gibb. J. and Anderson. B. H.. 'Vortex Flow Control Applied to Aircraft Intake Ducts', High Lift an Separation Control Conference. University of Bath, UK, 1995.

7 Briley, W. R. and McDonald, H., "Analysis and Computation of Viscous Subsonic Primary and Secondary Flow." AIAA Paper No. 79-1453. Reno NV, Jan. 1979.

8 Briley, W. R.. and McDonald. H.. "Three-Dimensional Viscous Flows with Large Secondary Velocities," Journal of Eluid Mechanics, March 1984, Vol. 144, pp. 47-77.

${ }^{9}$ Levy, R.. Briley, W. R., and McDonald, H., "Viscous Primary/Secondary Flow Analysis for Use with Nonorthogonal Coordinate Systems." AIAA Paper No. 830556. Reno. NV. Jan. 1983.

10 Anderson. B. H.. "The Aerodynamic Characteristics of Vortex Ingestion for the F/A-18 Inlet Duct." AIAA Paper No.
91-0130, Reno. NV. Jan. 1991.

11 McDonald. H.. and Camarata. F. J.: "An Extended Mixing Length for Computing the Turbulent Boundary-Layer Development. Proceedings, Stanford Conference of Turbulent Boundary Layers," Vol. I, Pub. by Stanford University, pp 83-98. 1969.

12 Reyner, T. A. and Flugge-Lotz. I.. "Interaction of a Shock Wave with a Laminar Boundary Layer." Internal Journal of Non-Linear Mechanics. Vol. 3. 1968.

13 Whitelaw, J. H., and Yu. S. C.. "Velocity Measurements in an S-Shaped Duct", Experiments in Fluids, Vol. 15, 1993. pp 364-367.

14 Anderson. B. H. and Farokhi. S.. "A Study of Three Dimensional Turbulent Boundary layer Separation and Vortex Flow Control Using Reduced Navier-Stokes Equations". Turbulent Shear Flow Symposium. Munich. Germany, Sept. 1991.

15 Anderson, B. H., Reddy, D. R.. and Kapoor. K. "A Comparative Study of Full Navier-Stokes and Reduced Navier Stokes Analyses for Separating Flows Within a Diffusing Inlet S-Duct," AIAA Paper No.93-2154, Montery. CA. June 1993.

${ }^{16}$ Kunik. W. G.,"Application of a Computational Model for Vortex Generators in Subsonic Internal Flows", AIAA Paper No. 86-1458, June 1986.

17 Willmer. A. C.. Brown. T. W. and Goldsmith. E. L.. "Effects of Intake Geometry on Circular Pitot Intake Performance at Zero and Low Forward Speeds". Aerodynamics of Power Plant Installation, AGARD CP301, Paper 5, Toulouse, France, May 1981,pp 51-56 


\section{REPORT DOCUMENTATION PAGE}

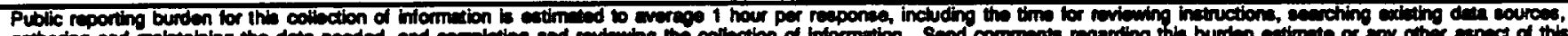

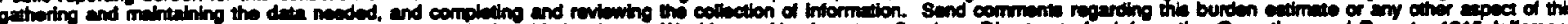

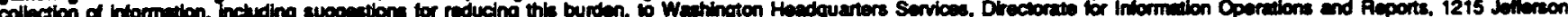

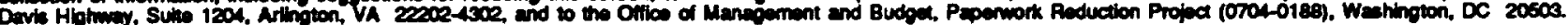

\begin{tabular}{|c|c|c|}
\hline 1. AGENCY USE ONLY (LOANO blank) & $\begin{array}{l}2 \text { REPOAT DATE } \\
\text { MaY } 1996\end{array}$ & $\begin{array}{l}\text { 3. REPPOAT TYPE AND DATES COVERED } \\
\text { Technical Memorandum }\end{array}$ \\
\hline
\end{tabular}

\section{TIIE AND SUBTIIL}

Vortex Generator Installation Studies on Steady State and

Dynamic Inlet Distortion

\section{AUTHOR(S)}

Bernhard $\mathrm{H}$. Anderson and James Gibb

\section{PERFOPIING ORGANIZATION NLAME(S) AND ADDRESS(ES)}

National Aeronautics and Space Administration

Lewis Research Center

Cleveland, Ohio 44135-3191

9. SPONSOFINGMONTOFINO AGENCY MANE(S) AND ADDPESS(ES)

National Aeronautics and Space Administration

Washington, D.C. 20546-0001

\section{FUNDING MLNGERS}

WU-505-62-52
8. PERFOPIMNG OPGANIZATION RIEPOFT MUMBER

E-10252
10. SPONSOFANGNONITOFING AGENCY REPOFT NUMBEA

NASA TM-107220

AIAA-96-3279

11. SUPPLENENTARY NOTES

Prepared for the 32nd Joint Propulsion Conference cosponsored by AIAA, ASME, SAE, and ASEE, Lake Buena Vista, Florida, July 13, 1996. Bernhard H. Anderson, NASA Lewis Research Center and James Gibb, Defence Research Agency, Bedford, MK416AE, England. Responsible person, Bernhard H. Anderson, organization code 2600. (216) 433-5822.

12a. DISTRIBUTONAVALABILTY STATEMENT 12b. DISTRABUTION COOE

Unclassified -Unlimited

Subject Category 07

This publication is available from the NASA Center for AeroSpace Information, (301) 621-0390.

13. ABSTRACT (Maximum 200 words)

The theoretical and experimental work carried out under the NASA/MOD Joint Aeronautical Program has shown that CFD vortex generator installations designs successfully managed inlet duct flow distortion and that significant benefits in flow unsteadiness at the engine face were also present. The main conclusions to date from the collaborative effort between NASA/Lewis and DRA/Bedford are as follows: (1) vortex generator installations can be designed to be effective over a wide range of inlet operating conditions using Computational Fluid Dynamics and formal optimization procedures, (2) reductions in steady state engine face distortion of up to $80 \%$ have been measured in the M2129 inlet S-duct using CFD designed vortex generator installations, (3) reductions in flow unsteadiness of up to $80 \%$ have been measured in the M2129 inlet S-duct using CFD designed vortex generator installations, and (4) the Rectuced Navier-Stokes code RNS3D is a useful tool to design vortex generator installations to manage engine face distortions over a wide range of inlet operating conditions.

14. SUBJECT TERMS

Inlets, engine; Computational Fluid Dynamics

15. MUMBER OF PAGES 11

16. PRICE CODE

A03

17. SECURTY CIASSIFICATION OF REPORT

Unclassified
18. SECURTY CLASSIFICATION of THIS PAGE Unclassified
19. SECUPTY CLASSIFICATION OF ABSTRACT Unclassified 


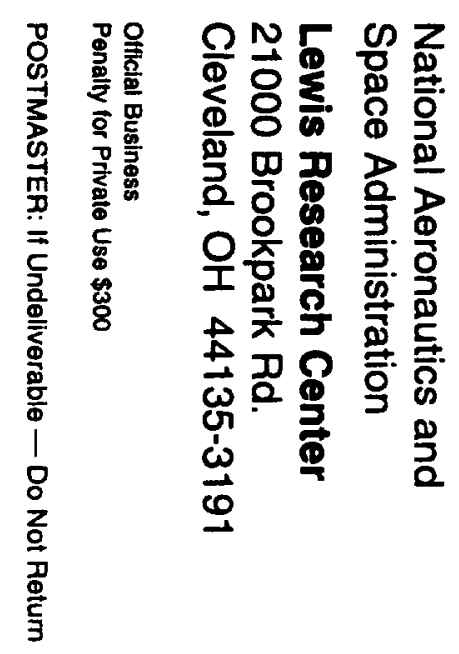

